\title{
Strong Convergence of an Implicit Iteration Algorithm for a Finite Family of Pseudocontractive Mappings
}

\author{
Yonghong Yao ${ }^{1}$ and Yeong-Cheng Liou' ${ }^{2}$ \\ ${ }^{1}$ Department of Mathematics, Tianjin Polytechnic University, Tianjin 300160, China \\ ${ }^{2}$ Department of Information Management, Cheng Shiu University, Kaohsiung 833, Taiwan
}

Correspondence should be addressed to Yonghong Yao, yaoyonghong@yahoo.cn

Received 2 December 2007; Accepted 2 January 2008

Recommended by Ram Verma

Strong convergence theorems for approximation of common fixed points of a finite family of pseudocontractive mappings are proven in Banach spaces using an implicit iteration scheme. The results presented in this paper improve and extend the corresponding results of Osilike, $\mathrm{Xu}$ and Ori, Chidume and Shahzad, and others.

Copyright $(2008$ Y. Yao and Y.-C. Liou. This is an open access article distributed under the Creative Commons Attribution License, which permits unrestricted use, distribution, and reproduction in any medium, provided the original work is properly cited.

\section{Introduction}

Let $E$ be a real Banach space and let $J$ denote the normalized duality mapping from $E$ into $2^{E^{*}}$ given by

$$
J(x)=\left\{x^{*} \in E^{*}:\left\langle x, x^{*}\right\rangle=\|x\|^{2}=\left\|x^{*}\right\|^{2}\right\},
$$

where $E^{*}$ denotes the dual space of $E$ and $\langle\cdot, \cdot\rangle$ denotes the generalized duality pairing. If $E^{*}$ is strictly convex, then $J$ is single valued. In the sequel, we will denote the single-value duality mapping by $j$.

Let $C$ be a nonempty closed convex subset of $E$. Recall that a self-mapping $f: C \rightarrow C$ is said to be a contraction if there exists a constant $\delta \in(0,1)$ such that

$$
\|f(x)-f(y)\| \leq \delta\|x-y\|, \quad \forall x, y \in C .
$$

We use $\Pi_{C}$ to denote the collection of all contractions on $C$. That is, $\Pi_{C}=\{f: f: C \rightarrow$ $C$ a contraction\}. 
A mapping $T$ with domain $D(T)$ and $R(T)$ in $E$ is called pseudocontractive if, for all $x, y \in D(T)$, there exists $j(x-y) \in J(x-y)$ such that

$$
\langle T x-T y, j(x-y)\rangle \leq\|x-y\|^{2} \text {. }
$$

We use $\operatorname{Fix}(T)$ to denote the fixed point set of $T$, that is, $\operatorname{Fix}(T)=\{x \in C: T x=x\}$.

Recently, $\mathrm{Xu}$ and Ori [1] have introduced an implicit iteration process below for a finite family of nonexpansive mappings. Let $T_{1}, T_{2}, \ldots, T_{N}$ be $N$ self-mappings of $E$ and suppose that $\bigcap_{i=1}^{N} \operatorname{Fix}\left(T_{i}\right) \neq \varnothing$, the set of common fixed points of $T_{i}, i=1,2, \ldots, N$. An implicit iteration process for a finite family of nonexpansive mappings is defined as follows with $\left\{t_{n}\right\}$ a real sequence in $(0,1), x_{0} \in E$ :

$$
\begin{gathered}
x_{1}=t_{1} x_{0}+\left(1-t_{1}\right) T_{1} x_{1}, \\
x_{2}=t_{2} x_{1}+\left(1-t_{2}\right) T_{2} x_{2}, \\
\vdots \\
x_{N}=t_{N} x_{N-1}+\left(1-t_{N}\right) T_{N} x_{N}, \\
x_{N+1}=t_{N+1} x_{N}+\left(1-t_{N+1}\right) T_{1} x_{N+1},
\end{gathered}
$$

which can be written in the following compact form:

$$
x_{n}=t_{n} x_{n-1}+\left(1-t_{n}\right) T_{n} x_{n}, \quad n \geq 1,
$$

where $T_{n}=T_{n} \bmod N$.

$\mathrm{Xu}$ and Ori proved the weak convergence of the above iterative process (1.5) to a common fixed point of a finite family of nonexpansive mappings $\left\{T_{n}\right\}_{n=1}^{N}$ in a Hilbert space. They further remarked that it is yet unclear what assumptions on the mapping and/or the parameters $\left\{t_{n}\right\}$ are sufficient to guarantee the strong convergence of the sequence $\left\{x_{n}\right\}$.

Very recently, Osilike [2] first extended $\mathrm{Xu}$ and Ori [1] from the class of nonexpansive mappings to the more general class of strictly pseudocontractive mappings in a Hilbert space. He proved the following two convergence theorems.

Theorem O1. Let $H$ be a real Hilbert space and let $C$ be a nonempty closed convex subset of $H$. Let $\left\{T_{i}\right\}_{i=1}^{N}$ be $N$ strictly pseudocontractive self-mappings of $C$ such that $\bigcap_{i=1}^{N}$ Fix $\left(T_{i}\right) \neq \varnothing$. Let $x_{0} \in C$ and let $\left\{\alpha_{n}\right\}_{n=1}^{\infty}$ be a sequence in $(0,1)$ such that $\lim _{n \rightarrow \infty} \alpha_{n}=0$. Then the sequence $\left\{x_{n}\right\}_{n=1}^{\infty}$ defined by

$$
x_{n}=\alpha_{n} x_{n-1}+\left(1-\alpha_{n}\right) T_{n} x_{n}, \quad n \geq 1,
$$

where $T_{n}=T_{n \bmod N}$, converges weakly to a common fixed point of the mappings $\left\{T_{i}\right\}_{i=1}^{N}$.

Theorem O2. Let $E$ be a real Banach space and let $C$ be a nonempty closed convex subset of E. Let $\left\{T_{i}\right\}_{i=1}^{N}$ be $N$ strictly pseudocontractive self-mappings of $C$ such that $\bigcap_{i=1}^{N}$ Fix $\left(T_{i}\right) \neq \varnothing$, and let $\left\{\alpha_{n}\right\}_{n=1}^{\infty}$ be a real sequence satisfying the conditions $0<\alpha_{n}<1, \sum_{n=1}^{\infty}\left(1-\alpha_{n}\right)=\infty$ and $\sum_{n=1}^{\infty}\left(1-\alpha_{n}\right)^{2}<\infty$. Let $x_{0} \in C$ and let $\left\{x_{n}\right\}_{n=1}^{\infty}$ be defined by

$$
x_{n}=\alpha_{n} x_{n-1}+\left(1-\alpha_{n}\right) T_{n} x_{n}, \quad n \geq 1,
$$

where $T_{n}=T_{n \bmod N}$. Then $\left\{x_{n}\right\}$ converges strongly to a common fixed point of the mappings $\left\{T_{i}\right\}_{i=1}^{N}$ if and only if $\liminf _{n \rightarrow \infty} d\left(x_{n}, F\right)=0$. 
Remark 1.1. We note that Theorem $\mathrm{O} 1$ has only weak convergence even in a Hilbert space and Theorem $\mathrm{O} 2$ has strong convergence, but imposed condition $\lim \inf _{n \rightarrow \infty} d\left(x_{n}, F\right)=0$.

In 2005, Chidume and Shahzad [3] also proved the strong convergence of the implicit iteration process (1.5) to a common fixed point for a finite family of nonexpansive mappings. They gave the following theorem.

Theorem CS. Let E be a uniformly convex Banach space, let $C$ be a nonempty closed convex subset of E. Let $\left\{T_{i}\right\}_{i=1}^{N}$ be $N$ nonexpansive self-mappings of $C$ with $\bigcap_{i=1}^{N}$ Fix $\left(T_{i}\right) \neq \varnothing$. Suppose that one of the mappings in $\left\{T_{i}\right\}_{i=1}^{N}$ is semicompact. Let $\left\{t_{n}\right\} \subset[\delta, 1-\delta]$ for some $\delta \in(0,1)$. From arbitrary $x_{0} \in C$, define the sequence $\left\{x_{n}\right\}$ by (1.5). Then $\left\{x_{n}\right\}$ converges strongly to a common fixed point of the mappings $\left\{T_{i}\right\}_{i=1}^{N}$.

Remark 1.2. Chidume and Shahzad gave an affirmative response to the question raised by $\mathrm{Xu}$ and Ori [1], but they imposed compactness condition on some mapping of $\left\{T_{i}\right\}_{i=1}^{N}$.

In this paper, we will consider a process for a finite family of pseudocontractive mappings which include the nonexpansive mappings as special cases. Let $f: C \rightarrow C$ be a contraction. Let $\left\{\alpha_{n}\right\},\left\{\beta_{n}\right\}$, and $\left\{\gamma_{n}\right\}$ be three real sequences in $(0,1)$ and an initial point $x_{0} \in C$. Let the sequence $\left\{x_{n}\right\}$ be defined by

$$
\begin{gathered}
x_{1}=\alpha_{1} f\left(x_{0}\right)+\beta_{1} x_{0}+\gamma_{1} T_{1} x_{1}, \\
x_{2}=\alpha_{2} f\left(x_{1}\right)+\beta_{2} x_{1}+\gamma_{2} T_{2} x_{2}, \\
\vdots \\
x_{N}=\alpha_{N} f\left(x_{N-1}\right)+\beta_{N} x_{N-1}+\gamma_{N} T_{N} x_{N}, \\
x_{N+1}=\alpha_{N+1} f\left(x_{N}\right)+\beta_{N+1} x_{N}+\gamma_{N+1} T_{1} x_{N+1},
\end{gathered}
$$

which can be written in the following compact form:

$$
x_{n}=\alpha_{n} f\left(x_{n-1}\right)+\beta_{n} x_{n-1}+\gamma_{n} T_{n} x_{n}, \quad n \geq 1,
$$

where $T_{n}=T_{n \bmod N}$.

Motivated by the works in [1-6], our purpose in this paper is to study the implicit iteration process (1.9) in the general setting of a uniformly smooth Banach space and prove the strong convergence of the iterative process (1.9) to a common fixed point of a finite family of pseudocontractive mappings $\left\{T_{i}\right\}_{i=1}^{N}$. The results presented in this paper generalize and extend the corresponding results of Chidume and Shahzad [3], Osilike [2], Xu and Ori [1], and others.

\section{Preliminaries}

Let $E$ be a Banach space. Recall the norm of $E$ is said to be Gateaux differentiable (and $E$ is said to be smooth) if

$$
\lim _{t \rightarrow 0} \frac{\|x+t y\|-\|x\|}{t}
$$


exists for each $x, y$ in its unit sphere $U=\{x \in E:\|x\|=1\}$. It is said to be uniformly Frechet differentiable (and $E$ is said to be uniformly smooth) if the limit in (2.1) is attained uniformly for $(x, y) \in U \times U$. It is well known that a Banach space $E$ is uniformly smooth if and only if the duality map $J$ is single valued and norm-to-norm uniformly continuous on bounded sets of $E$.

Recall that if $C$ and $D$ are nonempty subsets of a Banach space $E$ such that $C$ is nonempty closed convex and $D \subset C$, then a map $Q: C \rightarrow D$ is called a retraction from $C$ onto $D$ provided $Q(x)=x$ for all $x \in D$. A retraction $Q: C \rightarrow D$ is sunny provided $Q(x+t(x-Q(x)))=Q(x)$ for all $x \in C$ and $t \geq 0$ whenever $x+t(x-Q(x)) \in C$. A sunny nonexpansive retraction is a sunny retraction, which is also nonexpansive.

We need the following lemmas for proof of our main results.

Lemma 2.1 (see [7]). Let $E$ be a uniformly smooth Banach space, $C$ a closed convex subset of $E$, $T: C \rightarrow C$ a nonexpansive with Fix $(T) \neq \varnothing$. For each $f \in \Pi_{C}$ and every $t \in(0,1)$, then $\left\{x_{t}\right\}$ defined by

$$
x_{t}=t f\left(x_{t}\right)+(1-t) T x_{t}
$$

converges strongly as $t \rightarrow 0$ to a fixed point of $T$.

In particular, if $f=u \in C$ is a constant, then (2.2) is reduced to the sunny nonexpansive retraction of Reich from $C$ onto Fix $(T)$,

$$
\langle Q(u)-u, J(Q(u)-p)\rangle \leq 0, \quad p \in \operatorname{Fix}(T) .
$$

Lemma 2.2 (see [8]). Let E be a real uniformly smooth Banach space, then there exists a nondecreasing continuous function $b:[0, \infty) \rightarrow[0, \infty)$ satisfying

(i) $b(c t) \leq c b(t)$ for all $c \geq 1$;

(ii) $\lim _{t \rightarrow 0+} b(t)=0$;

(iii) $\|x+y\|^{2} \leq\|x\|^{2}+2\langle y, j(x)\rangle+\max \{\|x\|, 1\}\|y\| b(\|y\|)$, for all $x, y \in E$.

The inequality (iii) is called Reich's inequality.

Lemma 2.3 (see [9]). Let $\left\{a_{n}\right\}_{n=0}^{\infty}$ be a sequences of nonegative real numbers satisfying the property $a_{n+1} \leq\left(1-\gamma_{n}\right) a_{n}+\gamma_{n} \sigma_{n}, n \geq 0$, where $\left\{\gamma_{n}\right\}_{n=0}^{\infty} \subset(0,1)$ and $\left\{\sigma_{n}\right\}_{n=0}^{\infty}$ are such that

(i) $\sum_{n=0}^{\infty} \gamma_{n}=\infty$;

(ii) either $\lim \sup _{n \rightarrow \infty} \sigma_{n} \leq 0$ or $\sum_{n=0}^{\infty}\left|\gamma_{n} \sigma_{n}\right|<\infty$.

Then $\left\{a_{n}\right\}_{n=0}^{\infty}$ converges to 0 .

\section{Main results}

Theorem 3.1. Let $E$ be a uniformly smooth Banach space and let $C$ be a nonempty closed convex subset of E. Let $\left\{T_{i}\right\}_{i=1}^{N}$ be $N$ pseudocontractive self-mappings of $C$ such that $\bigcap_{i=1}^{N} \operatorname{Fix}\left(T_{i}\right) \neq \varnothing$. Let $\left\{\alpha_{n}\right\},\left\{\beta_{n}\right\}$, and $\left\{\gamma_{n}\right\}$ be three real sequences in $(0,1)$ satisfying the following conditions:

(i) $\alpha_{n}+\beta_{n}+\gamma_{n}=1$;

(ii) $\lim _{n \rightarrow \infty} \beta_{n}=0$ and $\lim _{n \rightarrow \infty}\left(\alpha_{n} / \beta_{n}\right)=0$;

(iii) $\sum_{n=0}^{\infty}\left(\alpha_{n} /\left(\alpha_{n}+\beta_{n}\right)\right)=\infty$. 
For $f \in \Pi_{C}$ and given $x_{0} \in C$ arbitrarily, let the sequence $\left\{x_{n}\right\}$ be defined by (1.9). Then $\left\{x_{n}\right\}$ converges strongly to a common fixed point $p$ of the mappings $\left\{T_{i}\right\}_{i=1}^{N}$, where $p=Q(f)$ is the unique solution of the following variational inequality:

$$
\langle(f-I) Q(f), j(z-Q(f))\rangle \leq 0 \quad \forall z \in \bigcap_{i=1}^{N} \operatorname{Fix}\left(T_{i}\right) .
$$

Proof. First, we observe that $\left\{x_{n}\right\}$ is bounded. Indeed, if we take a fixed point $p$ of $T$, noting that

$$
\begin{aligned}
x_{n} & -p \\
& =\left(1-\gamma_{n}\right)\left(\frac{\alpha_{n}}{1-\gamma_{n}} f\left(x_{n-1}\right)+\frac{\beta_{n}}{1-\gamma_{n}} x_{n-1}\right)+\gamma_{n} T_{n} x_{n}-p \\
& =\left(1-\gamma_{n}\right)\left[\frac{\alpha_{n}}{1-\gamma_{n}}\left(f\left(x_{n-1}\right)-f(p)\right)+\frac{\alpha_{n}(f(p)-p)}{1-\gamma_{n}}+\frac{\beta_{n}\left(x_{n-1}-p\right)}{1-\gamma_{n}}\right]+\gamma_{n}\left(T_{n} x_{n}-p\right) .
\end{aligned}
$$

It follows that

$$
\begin{aligned}
&\left\|x_{n}-p\right\|^{2} \\
&=\left(1-\gamma_{n}\right)\left\langle\frac{\alpha_{n}}{1-\gamma_{n}}\left(f\left(x_{n-1}\right)-f(p)\right)+\frac{\alpha_{n}(f(p)-p)}{1-\gamma_{n}}+\frac{\beta_{n}\left(x_{n-1}-p\right)}{1-\gamma_{n}}, j\left(x_{n}-p\right)\right\rangle \\
&+\gamma_{n}\left\langle T_{n} x_{n}-p, j\left(x_{n}-p\right)\right\rangle \\
& \leq\left(1-\gamma_{n}\right)\left\|\frac{\alpha_{n}}{1-\gamma_{n}}\left(f\left(x_{n-1}\right)-f(p)\right)+\frac{\alpha_{n}(f(p)-p)}{1-\gamma_{n}}+\frac{\beta_{n}\left(x_{n-1}-p\right)}{1-\gamma_{n}}\right\|\left\|x_{n}-p\right\|+\gamma_{n}\left\|x_{n}-p\right\|^{2},
\end{aligned}
$$

which implies that

$$
\begin{aligned}
\left\|x_{n}-p\right\| & \leq\left\|\frac{\alpha_{n}\left(f\left(x_{n-1}\right)-f(p)\right)}{1-\gamma_{n}}+\frac{\alpha_{n}(f(p)-p)}{1-\gamma_{n}}+\frac{\beta_{n}\left(x_{n-1}-p\right)}{1-\gamma_{n}}\right\| \\
& \leq \frac{\alpha_{n}}{1-\gamma_{n}}\|f(p)-p\|+\frac{\delta \alpha_{n}+\beta_{n}}{1-\gamma_{n}}\left\|x_{n-1}-p\right\| \\
& =\frac{(1-\delta) \alpha_{n}}{1-\gamma_{n}} \times \frac{\|f(p)-p\|}{1-\delta}+\left[1-\frac{(1-\delta) \alpha_{n}}{1-\gamma_{n}}\right]\left\|x_{n-1}-p\right\| \\
& \leq \max \left\{\frac{\|f(p)-p\|}{1-\delta},\left\|x_{n-1}-p\right\|\right\} .
\end{aligned}
$$

Now, an induction yields

$$
\left\|x_{n}-p\right\| \leq \max \left\{\frac{\|f(p)-p\|}{1-\delta},\left\|x_{0}-p\right\|\right\} .
$$

Hence $\left\{x_{n}\right\}$ is bounded, so are $\left\{f\left(x_{n}\right)\right\}$ and $\left\{T_{i} x_{n}\right\}$ for all $i=1,2, \ldots, N$. 
Observe that

$$
\left\|x_{n}-T_{n} x_{n}\right\| \leq \alpha_{n}\left\|f\left(x_{n-1}\right)-T_{n} x_{n}\right\|+\beta_{n}\left\|x_{n-1}-T_{n} x_{n}\right\| \longrightarrow 0
$$

Set $A_{n}=\left(2 I-T_{n}\right)^{-1}$ for all $n=1,2, \ldots, N$, it is well known that $\left\{A_{n}\right\}_{n=1}^{N}$ are all nonexpansive mappings and $\operatorname{Fix}\left(A_{n}\right)=\operatorname{Fix}\left(T_{n}\right)$ as a consequence of [10, Theorem 6]. Then we have

$$
\left\|x_{n}-A_{n} x_{n}\right\|=\left\|A_{n} A_{n}^{-1} x_{n}-A_{n} x_{n}\right\| \leq\left\|x_{n}-T_{n} x_{n}\right\| .
$$

It also follows from (3.6) that $\lim _{n \rightarrow \infty}\left\|x_{n}-A_{n} x_{n}\right\|=0$.

Next, we claim that

$$
\limsup _{n \rightarrow \infty}\left\langle f(p)-p, j\left(x_{n}-p\right)\right\rangle \leq 0 \quad p \in \bigcap_{i=1}^{N} \operatorname{Fix}\left(T_{i}\right),
$$

where $p=Q(f)=\lim _{t \rightarrow 0} z_{t}$ with $z_{t}$ being the fixed point of $z \mapsto t f(z)+(1-t) A_{n} z$ (see Lemma 2.1).

Indeed, $z_{t}$ solves the fixed point equation

$$
z_{t}=t f\left(z_{t}\right)+(1-t) A_{n} z_{t}
$$

Then we have

$$
z_{t}-x_{n}=(1-t)\left(A_{n} z_{t}-x_{n}\right)+t\left(f\left(z_{t}\right)-x_{n}\right)
$$

Thus we obtain

$$
\begin{aligned}
\left\|z_{t}-x_{n}\right\|^{2} \leq & (1-t)^{2}\left[\left\|A_{n} z_{t}-A_{n} x_{n}\right\|+\left\|x_{n}-A_{n} x_{n}\right\|\right]^{2} \\
& +2 t\left\langle f\left(z_{t}\right)-z_{t}, j\left(z_{t}-x_{n}\right)\right\rangle+2 t\left\|z_{t}-x_{n}\right\|^{2}
\end{aligned}
$$

Noting that

$$
\begin{aligned}
\left\langle f\left(z_{t}\right)-z_{t}, j\left(z_{t}-x_{n}\right)\right\rangle & =\left\langle f\left(z_{t}\right)-f(p), j\left(z_{t}-x_{n}\right)\right\rangle+\left\langle f(p)-z_{t}, j\left(z_{t}-x_{n}\right)\right\rangle \\
& \leq \delta\left\|z_{t}-p\right\|\left\|z_{t}-x_{n}\right\|+\left\langle f(p)-z_{t}, j\left(z_{t}-x_{n}\right)\right\rangle .
\end{aligned}
$$

Thus (3.11) gives

$$
\begin{aligned}
\left\|z_{t}-x_{n}\right\|^{2} \leq & (1-t)^{2}\left[\left\|z_{t}-x_{n}\right\|+\left\|x_{n}-A_{n} x_{n}\right\|\right]^{2}+2 \delta t\left\|z_{t}-p\right\|\left\|z_{t}-x_{n}\right\| \\
& +2 t\left\langle f(p)-z_{t}, j\left(z_{t}-x_{n}\right)\right\rangle+2 t\left\|z_{t}-x_{n}\right\|^{2} \\
\leq & (1-t)^{2}\left\|z_{t}-x_{n}\right\|^{2}+a_{n}(t)+2 \delta t\left\|z_{t}-p\right\|\left\|z_{t}-x_{n}\right\| \\
& +2 t\left\langle f(p)-z_{t}, j\left(z_{t}-x_{n}\right)\right\rangle+2 t\left\|z_{t}-x_{n}\right\|^{2}
\end{aligned}
$$

where

$$
a_{n}(t)=\left(2\left\|z_{t}-x_{n}\right\|+\left\|x_{n}-A_{n} x_{n}\right\|\right)\left\|x_{n}-A_{n} x_{n}\right\| \longrightarrow 0 \quad \text { as } n \longrightarrow \infty
$$


It follows that

$$
\left\langle z_{t}-f(p), j\left(z_{t}-x_{n}\right)\right\rangle \leq \frac{t}{2}\left\|z_{t}-x_{n}\right\|^{2}+\frac{1}{2 t} a_{n}(t)+\delta\left\|z_{t}-p\right\|\left\|z_{t}-x_{n}\right\|
$$

Letting $n \rightarrow \infty$ in (3.15) and noting (3.14) yields

$$
\limsup _{n \rightarrow \infty}\left\langle z_{t}-f(p), j\left(z_{t}-x_{n}\right)\right\rangle \leq \frac{t}{2} M+\delta M\left\|z_{t}-p\right\|
$$

where $M>0$ is a constant.

For (3.9), since $z_{t}$ strongly converges to $p$, then $\left\{z_{t}\right\}$ is bounded. Hence we obtain immediately that the set $\left\{z_{t}-x_{n}\right\}$ is bounded. At the same time, we note that the duality map $j$ is norm-to-norm uniformly continuous on bounded sets of $E$. By letting $t \rightarrow 0$ in (3.16), it is not hard to find that the two limits can be interchanged and (3.8) is thus proven.

Finally, we show that $x_{n} \rightarrow p$ strongly.

Indeed, using Lemma 2.2 and noting that (3.4), we obtain

$$
\begin{aligned}
\left\|x_{n}-p\right\|^{2} & \left\|\frac{\alpha_{n}}{1-\gamma_{n}}\left(f\left(x_{n-1}\right)-p\right)+\frac{\beta_{n}}{1-\gamma_{n}}\left(x_{n-1}-p\right)\right\|^{2} \\
\leq & \left(\frac{\beta_{n}}{1-\gamma_{n}}\right)^{2}\left\|x_{n-1}-p\right\|^{2}+2 \frac{\alpha_{n} \beta_{n}}{\left(1-\gamma_{n}\right)^{2}}\left\langle f\left(x_{n-1}\right)-p, j\left(x_{n-1}-p\right)\right\rangle \\
& +\max \left\{\left\|\frac{\beta_{n}}{1-\gamma_{n}}\left(x_{n-1}-p\right)\right\|, 1\right\} \frac{\alpha_{n}}{1-\gamma_{n}}\left\|f\left(x_{n-1}\right)-p\right\| b\left(\frac{\alpha_{n}}{1-\gamma_{n}}\left\|f\left(x_{n-1}\right)-p\right\|\right) \\
= & \left(\frac{\beta_{n}}{1-\gamma_{n}}\right)^{2}\left\|x_{n-1}-p\right\|^{2}+2 \frac{\alpha_{n} \beta_{n}}{\left(1-\gamma_{n}\right)^{2}}\left\langle f(p)-p, j\left(x_{n-1}-p\right)\right\rangle \\
& +2 \frac{\alpha_{n} \beta_{n}}{\left(1-\gamma_{n}\right)^{2}}\left\langle f\left(x_{n-1}\right)-f(p), j\left(x_{n-1}-p\right)\right\rangle \\
& +\max \left\{\left\|\frac{\beta_{n}}{1-\gamma_{n}}\left(x_{n-1}-p\right)\right\|, 1\right\} \frac{\left\|f\left(x_{n-1}\right)-p\right\| \alpha_{n}}{1-\gamma_{n}} b\left(\frac{\left\|f\left(x_{n-1}\right)-p\right\| \alpha_{n}}{1-\gamma_{n}}\right) \\
\leq & {\left[1-\frac{\alpha_{n}\left(\alpha_{n}+2 \beta_{n}\right)}{\left(\alpha_{n}+\beta_{n}\right)^{2}}\right]\left\|x_{n-1}-p\right\|^{2}+\frac{2 \alpha_{n} \beta_{n}}{\left(\alpha_{n}+\beta_{n}\right)^{2}} \delta\left\|x_{n-1}-p\right\|^{2} } \\
& +\frac{2 \alpha_{n} \beta_{n}}{\left(\alpha_{n}+\beta_{n}\right)^{2}}\left\langle f(p)-p, j\left(x_{n-1}-p\right)\right\rangle \\
+ & \max \left\{\frac{\beta_{n}}{1-\gamma_{n}}\left(x_{n-1}-p\right) \|, 1\right\} \frac{\left\|f\left(x_{n-1}\right)-p\right\| \alpha_{n}}{\alpha_{n}+\beta_{n}} b\left(\frac{\left\|f\left(x_{n-1}\right)-p\right\| \alpha_{n}}{\alpha_{n}+\beta_{n}}\right)
\end{aligned}
$$




$$
\begin{aligned}
= & {\left[1-\frac{\alpha_{n}\left(\alpha_{n}+2(1-\delta) \beta_{n}\right)}{\left(\alpha_{n}+\beta_{n}\right)^{2}}\right]\left\|x_{n-1}-p\right\|^{2}+\frac{\alpha_{n}\left(\alpha_{n}+2(1-\delta) \beta_{n}\right)}{\left(\alpha_{n}+\beta_{n}\right)^{2}} } \\
& \times\left\{\frac{2 \beta_{n}}{\alpha_{n}+2(1-\delta) \beta_{n}}\left\langle f(p)-p, j\left(x_{n-1}-p\right)\right\rangle\right. \\
& \left.\quad+\max \left\{\left\|\frac{\beta_{n}}{1-\gamma_{n}}\left(x_{n-1}-p\right)\right\|, 1\right\} \frac{\left\|f\left(x_{n-1}\right)-p\right\|\left(\alpha_{n}+\beta_{n}\right)}{\alpha_{n}+2(1-\delta) \beta_{n}} b\left(\frac{\left\|f\left(x_{n-1}\right)-p\right\| \alpha_{n}}{\alpha_{n}+\beta_{n}}\right)\right\} \\
= & \left(1-\lambda_{n}\right)\left\|x_{n-1}-p\right\|^{2}+\lambda_{n} \sigma_{n},
\end{aligned}
$$

where $\lambda_{n}=\alpha_{n}\left(\alpha_{n}+2(1-\delta) \beta_{n}\right) /\left(\alpha_{n}+\beta_{n}\right)^{2}$ and

$$
\begin{aligned}
\sigma_{n}= & \frac{2 \beta_{n}}{\alpha_{n}+2(1-\delta) \beta_{n}}\left\langle f(p)-p, j\left(x_{n-1}-p\right)\right\rangle+\max \left\{\left\|\frac{\beta_{n}\left(x_{n-1}-p\right)}{1-\gamma_{n}}\right\|, 1\right\} \\
& \times \frac{\left\|f\left(x_{n-1}\right)-p\right\|\left(\alpha_{n}+\beta_{n}\right)}{\alpha_{n}+2(1-\delta) \beta_{n}} \times b\left(\frac{\left\|f\left(x_{n-1}\right)-p\right\| \alpha_{n}}{\alpha_{n}+\beta_{n}}\right) .
\end{aligned}
$$

We observe that $\lim _{n \rightarrow \infty}\left(\left(\alpha_{n}+2(1-\delta) \beta_{n}\right) /\left(\alpha_{n}+\beta_{n}\right)\right)=2(1-\delta)$, then $\sum_{n=0}^{\infty} \lambda_{n}=\infty$ and $\max \left\{\left\|\left(\beta_{n} /\left(1-\gamma_{n}\right)\right)\left(x_{n-1}-p\right)\right\|, 1\right\}\left(\left\|f\left(x_{n-1}\right)-p\right\|\left(\alpha_{n}+\beta_{n}\right) /\left(\alpha_{n}+2(1-\delta) \beta_{n}\right)\right)$ is bounded. At the same time, from $\lim _{n \rightarrow \infty}\left(\alpha_{n} /\left(\alpha_{n}+\beta_{n}\right)\right)=0$, we have that $b\left(\left\|f\left(x_{n-1}\right)-p\right\| \alpha_{n} /\left(\alpha_{n}+\beta_{n}\right)\right) \rightarrow 0$. This implies that $\limsup _{n \rightarrow \infty} \sigma_{n} \leq 0$.

Now, we apply Lemma 2.3 and use (3.8) to see that $\left\|x_{n}-p\right\| \rightarrow 0$. This completes the proof.

Remark 3.2. Theorem 3.1 proves the strong convergence in the framework of real uniformly smooth Banach spaces. Our theorem extends Theorem O1 to the more general real Banach spaces. Our result improves Theorem O2 without condition $\lim \inf _{n \rightarrow \infty} d\left(x_{n}, F\right)=0$ and at the same time extends the mappings from nonexpansive mappings to pseudocontractive mappings.

Corollary 3.3. Let $E$ be a uniformly smooth Banach space and let $C$ be a nonempty closed convex subset of E. Let $\left\{T_{i}\right\}_{i=1}^{N}$ be $N$ pseudocontractive self-mappings of $C$ such that $\bigcap_{i=1}^{N} \operatorname{Fix}\left(T_{i}\right) \neq \varnothing$. Let $\left\{\alpha_{n}\right\},\left\{\beta_{n}\right\}$, and $\left\{\gamma_{n}\right\}$ be three real sequences in $(0,1)$ satisfying the following conditions:

(i) $\alpha_{n}+\beta_{n}+\gamma_{n}=1$;

(ii) $\lim _{n \rightarrow \infty} \beta_{n}=0$ and $\lim _{n \rightarrow \infty}\left(\alpha_{n} / \beta_{n}\right)=0$;

(iii) $\sum_{n=0}^{\infty}\left(\alpha_{n} /\left(\alpha_{n}+\beta_{n}\right)\right)=\infty$.

For fixed $u \in C$ and given $x_{0} \in C$ arbitrarily, let the sequence $\left\{x_{n}\right\}$ be defined by

$$
x_{n}=\alpha_{n} u+\beta_{n} x_{n-1}+\gamma_{n} T_{n} x_{n}, \quad n \geq 1 .
$$

Then $\left\{x_{n}\right\}$ converges strongly to a common fixed point $p$ of the mappings $\left\{T_{i}\right\}_{i=1}^{N}$, where $p=Q(u)$ is the unique solution of the following inequality:

$$
\langle u-Q(u), j(z-Q(u))\rangle \leq 0 \quad \forall z \in \bigcap_{i=1}^{N} \operatorname{Fix}\left(T_{i}\right),
$$

where $Q$ is a sunny nonexpansive retraction from $C$ onto $\bigcap_{i=1}^{N} \operatorname{Fix}\left(T_{i}\right)$. 
Corollary 3.4. Let E be a uniformly smooth Banach space and let $C$ be a nonempty closed convex subset of E. Let $\left\{T_{i}\right\}_{i=1}^{N}$ be $N$ nonexpansive self-mappings of $C$ such that $\bigcap_{i=1}^{N} \operatorname{Fix}\left(T_{i}\right) \neq \varnothing$. Let $\left\{\alpha_{n}\right\},\left\{\beta_{n}\right\}$, and $\left\{\gamma_{n}\right\}$ be three real sequences in $(0,1)$ satisfying the following conditions:

(i) $\alpha_{n}+\beta_{n}+\gamma_{n}=1$;

(ii) $\lim _{n \rightarrow \infty} \beta_{n}=0$ and $\lim _{n \rightarrow \infty}\left(\alpha_{n} / \beta_{n}\right)=0$;

(iii) $\sum_{n=0}^{\infty}\left(\alpha_{n} /\left(\alpha_{n}+\beta_{n}\right)\right)=\infty$.

For $f \in \Pi_{C}$ and given $x_{0} \in C$ arbitrarily, let the sequence $\left\{x_{n}\right\}$ be defined by (1.9). Then $\left\{x_{n}\right\}$ converges strongly to a common fixed point $p$ of the mappings $\left\{T_{i}\right\}_{i=1}^{N}$, where $p=Q(f)$ is the unique solution of the following variational inequality:

$$
\langle(f-I) Q(f), j(z-Q(f))\rangle \leq 0 \quad \forall z \in \bigcap_{i=1}^{N} \operatorname{Fix}\left(T_{i}\right)
$$

Corollary 3.5. Let E be a uniformly smooth Banach space and let $C$ be a nonempty closed convex subset of E. Let $\left\{T_{i}\right\}_{i=1}^{N}$ be $N$ nonexpansive self-mappings of $C$ such that $\bigcap_{i=1}^{N} \operatorname{Fix}\left(T_{i}\right) \neq \varnothing$. Let $\left\{\alpha_{n}\right\},\left\{\beta_{n}\right\}$, and $\left\{\gamma_{n}\right\}$ be three real sequences in $(0,1)$ satisfying the following conditions:

(i) $\alpha_{n}+\beta_{n}+\gamma_{n}=1$;

(ii) $\lim _{n \rightarrow \infty} \beta_{n}=0$ and $\lim _{n \rightarrow \infty}\left(\alpha_{n} / \beta_{n}\right)=0$;

(iii) $\sum_{n=0}^{\infty}\left(\alpha_{n} /\left(\alpha_{n}+\beta_{n}\right)\right)=\infty$.

For fixed $u \in C$ and given $x_{0} \in C$ arbitrarily, let the sequence $\left\{x_{n}\right\}$ be defined by

$$
x_{n}=\alpha_{n} u+\beta_{n} x_{n-1}+\gamma_{n} T_{n} x_{n}, \quad n \geq 1 .
$$

Then $\left\{x_{n}\right\}$ converges strongly to a common fixed point $p$ of the mappings $\left\{T_{i}\right\}_{i=1}^{N}$, where $p=Q(u)$ is the unique solution of the following inequality:

$$
\langle u-Q(u) p, j(z-Q(u))\rangle \leq 0 \quad \forall z \in \bigcap_{i=1}^{N} \operatorname{Fix}\left(T_{i}\right),
$$

where $Q$ is a sunny nonexpansive retraction from $C$ onto $\bigcap_{i=1}^{N} \operatorname{Fix}\left(T_{i}\right)$.

Remark 3.6. Corollary 3.5 improves Theorem CS without compactness assumption of mappings.

\section{Acknowledgments}

The authors are extremely grateful to the referee for his/her careful reading. The first author was partially supposed by National Natural Science Foundation of China, Grant no. 10771050. The second author was partially supposed by the Grant no. NSC 96-2221-E-230-003. 


\section{References}

[1] H. K. Xu and R. G. Ori, "An implicit iteration process for nonexpansive mappings," Numerical Functional Analysis and Optimization, vol. 22, no. 5-6, pp. 767-773, 2001.

[2] M. O. Osilike, "Implicit iteration process for common fixed points of a finite family of strictly pseudocontractive maps," Journal of Mathematical Analysis and Applications, vol. 294, no. 1, pp. 73-81, 2004.

[3] C. E. Chidume and N. Shahzad, "Strong convergence of an implicit iteration process for a finite family of nonexpansive mappings," Nonlinear Analysis, vol. 62, no. 6, pp. 1149-1156, 2005.

[4] Y. C. Liou, Y. Yao, and R. Chen, "Iteration scheme with perturbed mapping for common fixed points of a finite family of nonexpansive Mappings," Fixed Point Theory and Applications, vol. 2007, Article ID 29091, 10 pages, 2007.

[5] Y. C. Liou, Y. Yao, and K. Kimura, "Strong convergence to common fixed points of a finite family of nonexpansive mappings," Journal of Inequalities and Applications, vol. 2007, Article ID 37513, 10 pages, 2007.

[6] L. C. Ceng, N. C. Wong, and J. C. Yao, "Implicit predictor-corrector iteration process for finitely many asymptotically (quasi-)nonexpansive mappings," Journal of Inequalities and Applications, vol. 2006, Article ID 65983, 11 pages, 2006.

[7] H. K. Xu, "Viscosity approximation methods for nonexpansive mappings," Journal of Mathematical Analysis and Applications, vol. 298, no. 1, pp. 279-291, 2004.

[8] S. Reich, "An iterative procedure for constructing zeros of accretive sets in Banach spaces," Nonlinear Analysis, vol. 2, no. 1, pp. 85-92, 1978.

[9] H. K. Xu, "An iterative approach to quadratic optimization," Journal of Optimization Theory and Applications, vol. 116, no. 3, pp. 659-678, 2003.

[10] R. H. Martin Jr., "Differential equations on closed subsets of a Banach space," Transactions of the American Mathematical Society, vol. 179, pp. 399-414, 1973. 